\title{
Opportunities for the development of drowning interventions in West Bengal, India: a review of policy and government programs
}

\author{
M. Gupta ${ }^{1 *}$ (D, A. B. Zwi ${ }^{2}$ and J. Jagnoor ${ }^{3}$
}

\begin{abstract}
Background: Four million people living in the Indian Sundarbans region in the state of West Bengal face a particularly high risk of drowning due to rurality, presence of open water, lack of accessible health systems and poor infrastructure. Although the World Health Organization has identified several interventions that may prevent drowning in rural low-and middle-income country contexts, none are currently implemented in this region. This study aims to conduct contextual policy analysis for the development of a drowning program. Implementation of a drowning program should consider leveraging existing structures and resources, as interventions that build on policy targets or government programs are more likely to be sustainable and scalable.

Methods: A detailed content review of national and state policy (West Bengal) was conducted to identify policy principles and/or specific government programs that may be leveraged for drowning interventions. The enablers and barriers of these programs as well as their implementation reach were assessed through a systematic literature review. Identified policies and programs were also assessed to understand how they catered for underserved groups and their implications for equity.

Results: Three programs were identified that may be leveraged for the implementation of drowning interventions such as supervised childcare, provision of home-based barriers, swim and rescue skills training and community first responder training: the Integrated Child Development Scheme (ICDS), Self-Help Group (SHG) and Accredited Social Health Activist (ASHA) programs. All three had high coverage in West Bengal and considered underserved groups such as women and rural populations. Possible barriers to using these programs were poor government monitoring, inadequate resource provision and overburdening of community-based workers.
\end{abstract}

\footnotetext{
* Correspondence: mgupta@georgeinstitute.org.au

'The George Institute for Global Health, University of New South Wales, Level 5/1 King St, Newtown, NSW 2042, Australia

Full list of author information is available at the end of the article
}

(c) The Author(s). 2020 Open Access This article is licensed under a Creative Commons Attribution 4.0 International License, which permits use, sharing, adaptation, distribution and reproduction in any medium or format, as long as you give appropriate credit to the original author(s) and the source, provide a link to the Creative Commons licence, and indicate if changes were made. The images or other third party material in this article are included in the article's Creative Commons licence, unless indicated otherwise in a credit line to the material. If material is not included in the article's Creative Commons licence and your intended use is not permitted by statutory regulation or exceeds the permitted use, you will need to obtain permission directly from the copyright holder. To view a copy of this licence, visit http://creativecommons.org/licenses/by/4.0/ The Creative Commons Public Domain Dedication waiver (http://creativecommons.org/publicdomain/zero/1.0/) applies to the data made available in this article, unless otherwise stated in a credit line to the data. 
(Continued from previous page)

Conclusions: This is the first systematic analysis of both policy content and execution of government programs to provide comprehensive insights into possible implementation strategies for a health intervention, in this case drowning. Programs targeting specific health outcomes should consider interventions outside of the health sector that address social determinants of health. This may enable the program to better align with relevant government agendas and increase sustainability.

Keywords: Drowning, Asphyxia, Wounds and injuries, Policy making, India, Safety, Government programs, Implementation science

\section{Background}

Mortality from drowning presents a significant global burden, causing 320,000 deaths every year [1]. Drowning is defined as respiratory impairment resulting from submersion in liquid that may result in death or morbidity [2]. An estimated $90 \%$ of drowning events occur in lowand middle-income countries (LMICs) due to conditions such as poor infrastructure, poor regulation of water bodies and low awareness of water risks and swimming skills. Children aged 1-9 years old are at particular risk of drowning, especially in rural, coastal contexts where they are exposed to open water [3-5]. Drowning is in the top 5 causes of death for children aged 1-14 years old in 48 countries [1]. Drowning disproportionately affects underserved populations, especially those from lower socio-economic backgrounds in rural areas.

An estimated 62,000 drowning deaths occur in India each year, where it is the largest cause of child death by injury [6]. Despite this large burden, drowning is neglected as a public health issue. In particular, people living in the forested Sundarbans region in the state of West Bengal are exposed to a greater risk of drowning than many regions of India. It is remote and suffers from poor road and protective infrastructure such as fencing, unregulated open water, lack of safety awareness and inadequate health systems $[7,8]$. The 4 million people living here are from lower socio-economic backgrounds than the rest of the state [9]. The remote locations of drowning events lead to underreporting to hospitals and police stations, and hence there is a lack of data on drowning $[10,11]$. Climate change is increasing the frequency and intensity of flooding, exposing these populations to more dangerous conditions [7, 12, 13].

A drowning mortality survey in the Sundarbans (paper in preparation) found high rates of drowning in children aged 1-9 years old, at 244 deaths per 100,000 in children aged 1-4 years and 39 deaths per 100,000 in children aged 5-9 years. This is likely the leading cause of death for children in this region. Drowning interventions have not been implemented in the Sundarbans despite the risks. This paper presents the first component of formative research to develop a drowning intervention. The Steps for Quality Intervention Development (6SQuID) framework outlines the steps required for developing effective public health interventions [14]. According to this framework, once a health issue is identified, the micro, meso and macro context must be analysed to understand how the health intervention can be delivered [14-16]. In light of the Sustainable Development Goals (SDGs), the design of interventions should also consider issues of equity by analysing who is likely to benefit from, or be neglected by, an intervention $[17,18]$. This is particularly relevant in the Sundarbans which is home to higher proportions of underserved groups than other parts of the state $[7,8,18-20]$. Drowning is more likely to affect these marginalised populations due to poorer living conditions, including lower access to piped water and less protection from open water sources [11, 21].

The World Health Organization (WHO) recommends four evidence-informed community-based interventions to reduce drowning. These address known risk factors, such as inadequate child supervision, poor postdrowning first response and proximity of water to homes [3]. Based on existing studies, expert recommendations and national and global data sources, these were the installation of barriers controlling access to water (such as playpens and fencing), the provision of supervision for pre-school aged children with capable child care, and provision of basic swimming and rescue skills along with training adult bystanders in safe rescue and resuscitation [3]. Interventions are more likely to be sustainable if they leverage existing structures and resources, and align with internal frames, goals and targets of the government [22-24]. Our analysis determined which public policies and social interventions would support the recommended WHO drowning prevention interventions.

This paper examines how national and state policy, policy targets and government programs in West Bengal, India relate (or could be related) to drowning interventions. We identified which policies and programs could be leveraged to implement community-based drowning interventions. We also evaluated how drowning-related government programs were being implemented in West Bengal, and how well they incorporated equity considerations. Our objectives were to: [1] identify conceptualisation and perceptions of drowning within Indian policy 
[2]; identify policies and programs that relate to $\mathrm{WHO}$ drowning interventions [3]; understand the reach and implementation of relevant government programs identified in policy and [4]; identify barriers, enablers and equity considerations to the implementation of these government programs.

\section{Methods}

A systematic review of existing policy and literature was conducted to develop a comprehensive overview of the macro context in which a drowning intervention in the Sundarbans would operate. Policies and programs that may be leveraged for drowning interventions were identified. See Table 1 for inclusion criteria for data sources.

For this analysis, policies were defined as any government documents that outlined principles, rules or guidelines. Programs were defined as implementable activities run and/or funded by the government.

\section{Data sources}

Policy documents, peer-reviewed literature and grey literature sources were systematically sourced. Table 1 outlines the inclusion criteria for all sources.

\section{Policy documents}

The Sundarbans is located in the state of West Bengal and comes under the jurisdiction of both national Indian policy and West Bengal state policy. A thorough and structured review of relevant national and state-level websites was conducted to identify policies and programs that may be relevant to drowning interventions (Additional file 1).

A full text document review was conducted for all policy documents found. All policies were written in English. Only policies that were implementable in West Bengal as of July 2019 when this review was conducted were considered for analysis.

\section{Other sources}

After the identification of policies and programs that may be related to drowning, searches were conducted in both peer-reviewed and grey literature databases to gather literature on the implementation of these programs in West Bengal. These were then systematically screened by title and abstract, and remaining full texts analysed. See Additional files 2 and 3 for full search strategies, including list of databases and search terms.

Papers providing evaluations of government programs were assessed on the GRADE process, and articles rated 'Very Low' were removed [25]. Only literature analysing data from 1999 to July 2019 were considered.

\section{Analysis}

For each policy identified, content analysis by the primary investigator identified [1] how drowning was conceptualised (including underlying assumptions, perceptions, definitions) [2]; policy and program relationships with WHO drowning reduction interventions; and [3] government targets and programs relating to child health, education or wellbeing.

Documents that did not discuss any policies or programs relating to drowning were excluded. Documents that discussed physical safety either in water or from water, such as relating to fencing around water bodies, were included.

To assess considerations of equity in policy and program design, policies that exhibited linkages to drowning interventions were analysed using the PROGRESS-PLUS framework [26] and a modified Equiframe framework [27]. The PROGRESS-PLUS framework identified which underserved groups were acknowledged. The Equiframe framework was modified to be applicable to non-health sectors including education and rural development, by removing health-specific criteria and language. This was used to analyse how well policies catered to the rights of underserved groups in rural contexts (See Additional file 4 for Equiframe Framework and modifications made). Analyses from these frameworks allowed us to build an

Table 1 Inclusion Criteria for data sources

\begin{tabular}{|c|c|}
\hline Data source & Inclusion Criteria \\
\hline $\begin{array}{l}\text { Government policy } \\
\text { documents }\end{array}$ & $\begin{array}{l}\text { - Currently implementable as of July } 2019 \\
\text { - Implementable in West Bengal } \\
\text { - Discussion of principles, goals or programs that relate to drowning and/or WHO-recommended drowning reduction } \\
\text { interventions }\end{array}$ \\
\hline Grey literature & $\begin{array}{l}\text { - Published from } 1999 \text { to } 2019 \\
\text { - Discussion or evaluation of policy or programs in West Bengal that relate to drowning and/or WHO-recommended } \\
\text { drowning reduction programs } \\
\text { - If evaluation of a government program, GRADE score of Very Low was excluded }\end{array}$ \\
\hline Peer-reviewed articles & $\begin{array}{l}\text { - Published from } 1999 \text { to } 2019 \\
\text { - Discussion or evaluation of policy or programs in West Bengal that relate to drowning and/or WHO-recommended } \\
\text { drowning reduction programs } \\
\text { - If evaluation of a government program, GRADE score of Very Low was excluded }\end{array}$ \\
\hline
\end{tabular}


understanding of the treatment of underserved populations in drowning-related policy and programs.

To make judgements on the enablers and barriers to government program implementation in West Bengal, peer-reviewed and grey literature were synthesised through a narrative approach [28].

\section{Results}

\section{Document search results}

A total of 18 policy documents were identified and 48 peer reviewed articles were included for the narrative evaluation of drowning-related government programs. See Additional file 5 for PRISMA flow diagram of search results and Additional file 6 for full list of policy documents included in analysis.

\section{Drowning and drowning reduction in policy}

The policy review found very limited acknowledgement of drowning in any policy aside from some mention of drowning in disaster-related policy. The National Disaster Management Plan 2016 acknowledged drowning as a cause of death during disasters. However, no specific mechanisms to avoid drowning were discussed. No other policy document specifically mentioned drowning (or physical water safety).

Health-related policy, including the National Health Policy 2017, showed greater focus on noncommunicable diseases and included only minor reference to injuries. Policy related to the repair and management of water bodies, such as the National Water Policy 2012 and the Scheme on Repair, Renovation and
Restoration (RRR) of Water Bodies under PMKSY (HKKP) 2017, did not consider physical safety around water bodies. Like national-level policy, state-level policies from West Bengal did not mention drowning or physical water safety.

\section{Policy linkages to drowning interventions}

The review identified which policies described general principles or specific programs that related to the four drowning interventions recommended by WHO. Figure 1 shows how many policies mapped against each of the four recommended interventions followed by Table 2 which highlighted which programs were applicable. Policies that included principles relating to drowning reduction interventions did not necessarily specify programs to address these.

Table 2 summarises the government programs identified in relation to each WHO intervention. These programs were currently implemented by the National or West Bengal Government in the Sundarbans region as of July 2019.

The discussion below reflects on both the policies and programs that were identified that may be of value in taking forward specific drowning interventions.

\section{Barriers and fencing}

A few policies stated principles that aligned with the provision of barriers (Fig. 1). For example, the National Policy for Children 2013 acknowledged that all children have the right to a safe, secure and protective environment, including at home. The National Disaster

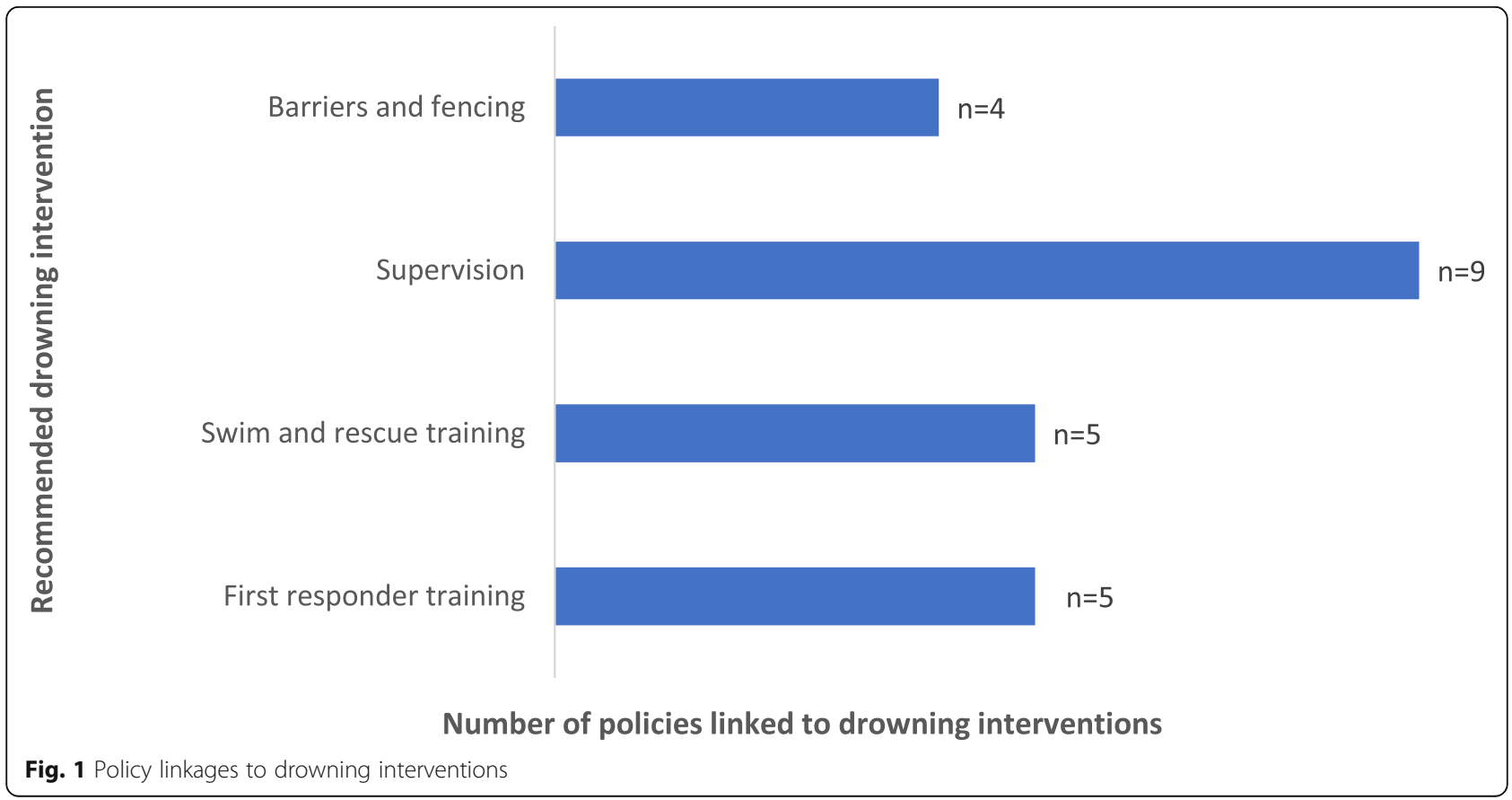


Table 2 Programs that may contribute to drowning interventions

\begin{tabular}{|c|c|c|c|c|}
\hline \multirow[t]{2}{*}{ Relevant government program identified in policy } & \multicolumn{4}{|c|}{ Potential contribution to recommended drowning interventions } \\
\hline & $\begin{array}{l}\text { Barriers and } \\
\text { fencing }\end{array}$ & $\begin{array}{l}\text { Supervised safe } \\
\text { spaces }\end{array}$ & $\begin{array}{l}\text { Swim and rescue } \\
\text { training }\end{array}$ & $\begin{array}{l}\text { First responder } \\
\text { training }\end{array}$ \\
\hline Integrated Child Development Scheme (ICDS) & No & Yes & No & No \\
\hline Mahatma Gandhi National Rural Employment Guarantee Act (MNREGA) 2005 & No & Yes & No & No \\
\hline Rajiv Gandhi National Crèche Scheme for the Children of Working Mothers 1994 & No & Yes & No & No \\
\hline $\begin{array}{l}\text { National Bank for Agriculture and Rural Development (NABARD) Self-Help Group } \\
\text { Bank Linkage Program }\end{array}$ & Yes & Yes & Yes & Yes \\
\hline Accredited Social Health Activist (ASHA) program & Yes & Yes & Yes & Yes \\
\hline Village Health, Sanitation and Nutrition Committees (VHSNC) & Yes & Yes & Yes & Yes \\
\hline
\end{tabular}

Management Plan 2016 stated that dams and reservoirs should be enhanced for safety. However, the mechanisms through which safe environments should be ensured were not clearly defined, and no government programs had been introduced that aimed to provide physical protection from water bodies.

\section{Supervised safe spaces}

The provision of supervised safe spaces for children was the most supported drowning-related intervention in policy. Education policy, such as the Early Childhood Care and Education Policy 2013 and National Policy on Education 1992 both stated that children have the right to free early childhood education up to the age of 6 years old, provided through supervised crèche-based programs.

Three programs that provide crèche-based supervision were identified. Firstly, the Indian Government introduced and implemented the Integrated Child Development Scheme (ICDS). The ICDS sets up local Anganwadi centres, where children are provided basic early childhood education and nutritionally-sufficient meals by locally trained women. West Bengal also launched Shishu Aloy in 2015, which aimed to transform some Anganwadi centres into enhanced early childhood learning centres with a structured pre-school curriculum.

A second program identified was the Mahatma Gandhi National Rural Employment Guarantee Act (MNREGA) 2005, which guaranteed 100 days of paid work to rural workers in the country. This program provisioned that a crèche service must be provided in any workplace where more than five children aged under 6 years old attend with their mothers.

Lastly, the Rajiv Gandhi National Crèche Scheme for the Children of Working Mothers 1994 aimed to provide day-care facilities for children aged 6 months to 6 years in both urban and rural community-based settings.

\section{Swim and rescue training}

There was no policy requirement found for children to learn swimming skills. Education policy, such as the $\mathrm{Na}$ tional Policy on Education 1992, necessitated the provision of physical activity classes in schools with the appropriate infrastructure (Fig. 1). However, policy did not identify swimming as a requirement within this. No specific swim and rescue training programs have been introduced by government.

\section{First responder training}

Policy focussed on building the capacity of communities to manage their own health and disaster response. From this view, the principle of providing first responder training was well supported. The National Health Policy 2017 aimed to increase the number of 'health volunteers' in communities who may act as first responders for health concerns. The National Disaster Management Plan 2016 and West Bengal State Disaster Management Policy and Framework also required community members, especially local leaders, to be trained in first response to respond to accidents and natural disasters. However, no specific government programs to provide First Responder training had been introduced in West Bengal based on these national directions.

\section{Comprehensive programs}

However, three valuable programs that may play facilitative or implementation roles across all four drowning interventions were also identified.

Firstly, Self-Help Group (SHG) programs, including the National Bank for Agriculture and Rural Development (NABARD) Self-Help Group Bank Linkage Program and the National Rural Livelihoods Mission, were identified as possible facilitators for program delivery. These programs formed support groups in villages for the provision of loans, mostly with women. The National Policy for the Empowerment of Women 2001 had identified SHGs as a mode through which social and economic development programs can be implemented in communities.

Secondly, the Accredited Social Health Activist (ASHA) program was mandated in the National Health Mission 2013 policy. The ASHA program trained and deployed community-based maternal and child health workers to 
act as the interface between the community and public health system. They were tasked with educating and mobilising communities on health issues through household visits and community meetings.

Thirdly, the National Health Mission 2013 detailed the establishment of Village Health, Sanitation and Nutrition Committees (VHSNCs), which were sub-committees under the local government (Gram Panchayats) tasked with overseeing programs related to health and its social determinants.

\section{Equity considerations in policy}

Particular barriers faced by women were mentioned in $67 \%$ of the policy documents (See Fig. 2). Place of residence was acknowledged in $61 \%$ of policies and socioeconomic status in 50\%. Social capital, educational background, occupation and religion were rarely discussed. Only two policies acknowledged more than half of the PROGRESS-PLUS groups: the National Health Policy 2017 and the National Policy for the Empowerment of Women 2001 (Fig. 2).

Based on the Equiframe Framework, 78\% ( $n=14)$ of policies acknowledged that programs should be tailored to meet the needs of underserved groups, and 72\% $(n=$ 13) recognised that underserved groups were capable and had a right to be involved in decision making. 61\% $(n=11)$ of policies also recognised explicitly that underserved groups were productive contributors to society, and 56\% $(n=10)$ supported underserved groups' physical, economic, and information access to services. However, few policies aimed to protect the privacy of underserved groups' information, ensured programs were tailored to the person's characteristics, or acknowledged the role of family in the impact of services. See
Table 3 for the number of policies that addressed each Equiframe domain.

Policies that linked to supervision-based interventions were more likely to protect the rights of underserved groups. For example, both the Early Childhood Care and Education Policy 2013 and the National Population Policy 2016 catered to $80 \%(n=12)$ of the applicable Equiframe criteria, and MGNREGA and catered to $77 \%$ $(n=10)$ of the applicable criteria. However, water and disaster-related policies, which often considered First Responder training and barriers and fencing, included few or no equity considerations. Health-related policy reflected only half of the Equiframe criteria.

\section{Implementation of programs with linkages to drowning reduction}

As discussed above, a range of government programs were identified in policy that may be leveraged in support for drowning reduction. The following reviews what is known about the implementation of these programs in West Bengal based on a systematic review of the peer-reviewed literature.

\section{Integrated child development scheme (ICDS)}

The Integrated Child Development Scheme (ICDS) is delivered through community-based Anganwadi centres. A trained female Anganwadi worker and assistant are responsible for running the centre 4 hours per day from 7 to $11 \mathrm{am}$. They are tasked with providing early childhood education (ECE) and nutritionally-sufficient meals [29, 30]. In West Bengal, the lowest tier of local government, the Gram Panchayat, is responsible for implementing the ICDS program [31]. Anganwadi workers are paid a stipend and are considered volunteers [32].

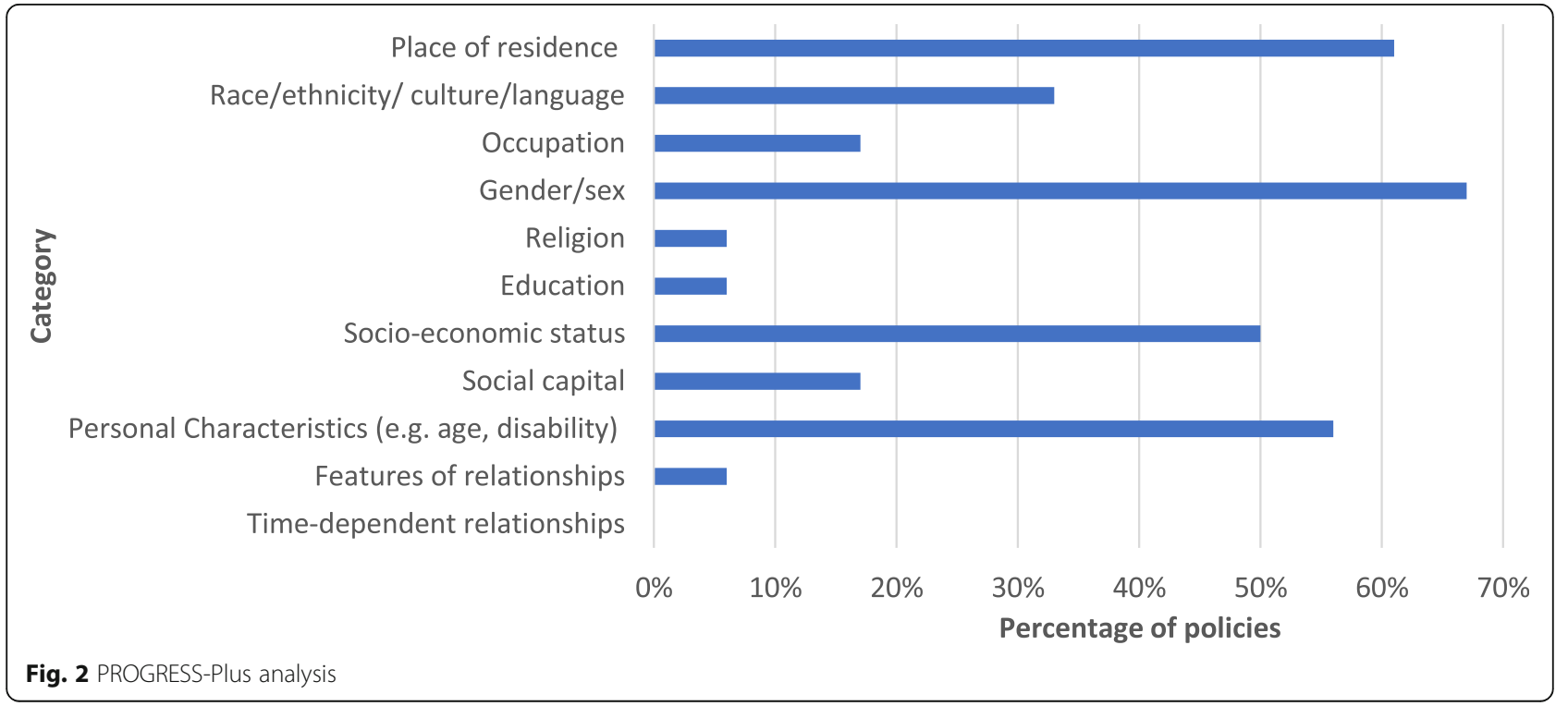


Table 3 Equiframe analysis

\begin{tabular}{|c|c|}
\hline Domain & $\begin{array}{l}\text { Number of } \\
\text { policies }\end{array}$ \\
\hline Does the policy support the rights of underserved groups with equal opportunity in receiving services? & 9 \\
\hline Does the policy support the rights of underserved groups with individually tailored services to meet their needs and choices? & 14 \\
\hline Does the policy indicate how underserved groups may qualify for specific benefits relevant to them? & 5 \\
\hline Does the policy recognize the capabilities existing within underserved groups? & 13 \\
\hline $\begin{array}{l}\text { Does the policy support the right of underserved groups to participate in the decisions that affect their lives and enhance their } \\
\text { empowerment? }\end{array}$ & 10 \\
\hline Are underserved groups protected from harm during their interaction with health and related systems? & 5 \\
\hline Does the policy support the right of underserved groups to be free from unwarranted physical or other confinement? & 5 \\
\hline $\begin{array}{l}\text { Does the policy support the right of underserved groups to consent, refuse to consent, withdraw consent, or otherwise control or } \\
\text { exercise choice or control over what happens to him or her? }\end{array}$ & 6 \\
\hline Does the policy address the need for information regarding underserved groups to be kept private and confidential? & 1 \\
\hline Does the policy recognize that underserved groups can be productive contributors to society? & 11 \\
\hline Does the policy recognize the value of the family members of underserved groups in addressing health and safety needs? & 6 \\
\hline $\begin{array}{l}\text { Does the policy recognize that individual members of underserved groups may have an impact on the family members, requiring } \\
\text { additional support from health or other related services? }\end{array}$ & 2 \\
\hline $\begin{array}{l}\text { Does the policy ensure that services respond to the beliefs, values, gender, interpersonal styles, attitudes, cultural, ethnic, or } \\
\text { linguistic aspects of the person? }\end{array}$ & 5 \\
\hline Does the policy specify to whom, and for what, services providers are accountable? & 9 \\
\hline Does the policy support underserved groups' physical, economic, and information access to services? & 10 \\
\hline
\end{tabular}

Overall, $88 \%$ of villages in West Bengal have access to an Anganwadi centre, compared to 45\% nationally [33]. However, cross-sectional survey data in two districts found that $27 \%$ of centres documented as operational were not running [34]. The true coverage of Anganwadi centres is likely to be lower than reported.

Implementation of ECE in Anganwadi centres is variable across the state, with only $60-85 \%$ of centres in each district providing this service [30,35-37]. A crosssectional study found that where provided, the duration of ECE activities averaged at only $60 \mathrm{~min}$, below the 120 min prescribed in policy. In addition, only $10 \%$ of centres had sufficient floor space for indoor activities, 33\% did not have any materials for activities, and none ran activities that were age appropriate. One study found that only $33 \%$ of children enrolled at the centre remained to participate in ECE [38].

A key barrier to implementing ECE in Anganwadi centres was the lack of an educational curriculum against which the services could be assessed. In addition, Anganwadi workers had limited resources and time to run ECE activities between their other responsibilities, and viewed the service as effortful [32, 35, 39]. Anganwadi centres may require additional resources in order to provide these services [40].

The ICDS program suffers from poor supervision and administration. Funding is often inadequate for rent, food and materials, and corrupt practices in higher levels of administration have occurred [32]. Furthermore, there is limited capacity to provide ongoing training, supervision and support of Anganwadi workers in managing on-ground implementation [41]. Although many Indian policies highlight ECE as a right, little emphasis is placed on ECE activities by supervisors [35].

\section{Shishu Aloy}

In 2015, the West Bengal government launched the Shishu Aloy program to set up enhanced Anganwadi centres that focused on early childhood education with a structured curriculum. However, there is no data available on this program's coverage and implementation success.

\section{Self-help group (SHG) programs}

The National Bank for Agriculture and Rural Development (NABARD) Self-help Group Bank Linkage program and the National Rural Livelihoods Mission are two programs centred on supporting mainly women through support groups. Although these two programs are independent, the basic models are similar [42, 43]. Villagebased self-help groups are formed by partnering NGOs and banks and linked to a financial institution for the provision of loans [44]. They also become involved in the provision of non-public services, such as providing training on agricultural techniques and providing childcare and healthcare $[45,46]$.

West Bengal has one of the greatest reaches of SHG programs in the country, with $51-75 \%$ of rural 
households being covered [47-50]. SHGs in West Bengal have been found to be effective in increasing women's income, providing better access to credit, reducing reliance on local money-lenders, reducing physical labour for members, increasing members' autonomy, increasing employment, improving access to health information and services, reducing rural poverty and empowering women with decision making power in their families and communities [19, 47, 51-59].

Nevertheless, challenges are evident. Firstly, there is often inadequate mentorship from the linked banks and NGOs for navigating the financial system $[51,52,60$, 61]. This is attributable to the absence of a clear chain of authority and accountability in funding structures [52, 62]. Secondly, women still bear the brunt of domestic work in rural communities, which may inhibit their ability to be involved in community activities [53, 63]. Operational issues have also been reported, where regularity of meetings and coordination between members may be poor [51].

The benefits and function of SHGs varies across religious and caste groups. Economic and political benefits have been found to be higher for upper caste Hindus than scheduled caste Hindus or Muslims, as they start with greater social mobility, higher incomes and better access to markets and technologies [19, 51]. Muslim women in particular see fewer improvements in business profits or health outcomes compared to Hindu women, possibly due to greater restrictions on women's roles and mobility [64].

\section{Village health, sanitation and nutrition committees}

The National Rural Health Mission set up Village Health, Sanitation and Nutrition Committees at the village level. These are sub-committees to the Gram Panchayat that coordinate collective actions on issues related to health and its social determinants. This includes overseeing the functioning of Anganwadi Centres and facilitating the work of front line health workers in the community [65]. 29.4\% of villages in West Bengal have VHSNCs, similar to the national average $[66,67]$. However, there is no information on their effectiveness and involvement in on-ground implementation in rural West Bengal.

\section{Rajiv Gandhi National Crèche Scheme for working mothers}

This program seeks to open crèche services for working mothers within communities. A key difference between these crèches and Anganwadi centres is that they run for $7.5 \mathrm{~h}$ each day, rather than half days. Currently there are 1636 crèches operating in West Bengal under this scheme, serving 40,900 children. However, the coverage of centres is low due to insufficient funding for these centres, and delays in payments to implementing agencies [68].

\section{Mahatma Gandhi National Rural Employment Guarantee act (MGNREGA)}

In West Bengal, 33\% of the labour employed through MGNREGA are women [59]. However, evidence from surveys conducted in West Bengal indicate that few workplaces have functioning childcare facilities available for use, and women are not aware of their right to request these services. Gram Panchayats also do not view the provision of childcare services a priority and are not taking actions to ensure set up $[59,69,70]$.

\section{Accredited social health activist (ASHA) program}

The Accredited Social Health Activist (ASHA) program is part of the National Health Mission strategy. In 2016, there were 47,204 ASHAs employed in West Bengal at a population density of 1 per 1317 population. This is $77 \%$ of the target of 1 per 1000 population [71]. ASHAs in West Bengal perform above average compared to the other states, showing higher members of visitations to households and greater involvement in sanitation education and toilet construction [72]. However, ASHAs in West Bengal are rarely fulfilling maternal support duties, with 7\% of ASHAs escorting women to health centres at the time of delivery, and only $14 \%$ visiting on the first day of birth. One study in the Howrah District of West Bengal found that half of ASHA workers were overburdened. In addition, Muslim ASHAs showed lower performance due to lower educational attainment and less support from Anganwadi workers [73].

\section{Discussion}

This paper aimed to develop a comprehensive understanding of the macro level policy context offering potential for drowning interventions. The results show a severe lack of awareness of drowning as an issue in policy. This is likely to result from a lack of available data on drowning and cultural beliefs that drownings are "accidents" $[10,11]$. The majority of data collection systems in India such as the Samples Registration System and District Level Household and Facility Survey collect information on deaths caused by injury more broadly but not specifically drowning deaths. Drowning is specified in police data (called the National Crime Records Bureau data) and in Medical Death Certificate data which feeds into the Vital Registration System, but low reporting to police stations and hospitals leads to a vast underestimate. Deaths are unlikely to be reported due to the rurality of incidents and the high number of deaths at the place of drowning that do not require medical attention. In addition, there are few legal implications of drowning 
deaths for both families and police as they are largely accidental and involve children.

\section{Building on pre-existing government programs}

The ICDS program, ASHA program and SHGs programs are all government programs that may be leveraged for drowning interventions. While the ICDS program may be optimised for child supervision, the ASHA and SHG programs have the flexibility to be leveraged across the range of drowning interventions.

\section{Integrated child development scheme (ICDS)}

The ICDS program stipulates providing $2 \mathrm{~h}$ of early childhood education activities for children aged 3-6 years old through Anganwadi centres. They have the potential to be used for structured supervision programs by extending ECE activity timings. Angwanwadi workers view themselves as respectable teachers and are motivated to contribute to initiatives that enhance child health outcomes [32]. They may also be used as a source of information on child deaths by drowning, as they already collect information on a range of child issues.

If Anganwadi centres are to be used for childcare services, additional factors must be considered. Firstly, Anganwadi workers are already heavily burdened in their duties and already struggle to provide the 2 hours of daily ECE activities mandated [32]. They are involved in a range of activities including community-level data collection on child issues and children's meals. The workloads of Anganwadi workers would need to be re-assessed to ensure that childcare services can be sustainably provided.

Low participation in the Anganwadi childcare program suggests that parents may not see the value in ECE. Mothers have also reported low levels of trust in Anganwadi workers to provide quality and safe services [34, 74]. Community trust building exercises will be required to encourage mothers to send their children for childcare services offered.

Another consideration is the effect of caste and religion on service provision. Children from a different caste or religion to the Anganwadi worker are sometimes treated poorly. Muslim attendance at Anganwadi centres is also lower compared to other groups [75, 76]. The provision of childcare services in a diverse community must understand and take account of these dynamics.

Anganwadi program policy acknowledged gender norms and rurality as barriers to access. It is important that ICDS addresses the effects of gender on access, as it is largely mothers who bring children to Anganwadi centres $[34,77]$.

\section{ASHAs}

ASHA workers are heavily involved in the community and have close relationships with women, making them advantageous for intervention delivery. However, as with Anganwadi workers, a key consideration for the use of ASHA workers is that they are overburdened with many duties such as household visits, data collection, disseminating vaccination information and more. The total number of tasks ASHAs must perform has increased from six in 2005 to 28 in 2017 [78]. ASHA workers must also attend to women in labour at short notice. Hence, ASHAs may be involved in community mobilisation activities such as engaging communities in first responder training or barrier installation, but are unlikely to have the time to provide child supervision or swim training themselves.

Poor consideration of equity in health-related policy may also be problematic when ensuring any interventions delivered by ASHAs cater to different groups, especially as ASHAs from minority groups have been shown to have poorer performance [73]. To ensure equitable reach of programs, barriers faced by some ASHAs should be identified and addressed with differential strategies and support.

\section{Self-help groups}

Self-help groups could be leveraged in the implementation and support of any of the drowning prevention programs, given their high coverage of rural households and involvement in community-based social activities. They are also largely composed of women who are viewed culturally as the main carers of children. As self-help groups programs face less regulation and governmentlevel constraints compared to the ASHA and ICDS programs, they may be simpler to engage in implementation.

\section{Government programs less feasible for drowning interventions}

While the Mahatma Gandhi National Rural Employment Guarantee Act (MGNREGA) includes a provision to provide childcare services to working women, this scheme will not cover a large number of children. The participation rate of women in the formal workforce is low, particularly in rural areas [79]. Poor coverage of the Rahul Ghandi Crèche Scheme for Working Mothers and Village Health, Sanitation and Nutrition Committees also reduce its usefulness for the implementation of a region-wide drowning intervention.

\section{Practical considerations of leveraging existing government programs}

While documented policy provides a window into government programs that may be leveraged for drowning interventions, it is essential to understand government decision makers' perceptions towards drowning [23, 80]. To ascertain which of the above discussed government 
programs can be feasibly leveraged, government processes behind the implementation of these programs must be understood. Furthermore, interactions between government decision makers, implementers and community-based staff should be taken into account in intervention design. This ensures that appropriate stakeholders are engaged and implementation can occur with governmental cooperation [81, 82]. Further qualitative research with policy makers and government implementers will capture their perspectives.

Policies and programs from other sectors should be considered when designing programs to address health outcomes especially if they address the social determinants of health [83]. This broadens the scope for health researchers and planners to engage with different government sectors to consider a wider range of intervention designs. For example, the ICDS and Self-help Group programs come under the Ministry of Women and Child Development and are linked with the Ministry of Education, while the ASHA program sits under the state level Ministry of Health. The policies related to first responder training and barriers relate to water infrastructure and disaster-related ministries. Inter-sectoral collaboration is required to implement these drowning reduction interventions.

The challenges for inter-sectoral collaboration are well-noted and must be considered. In many LMIC contexts, district governments are the main implementers of cross-sectoral programs, but coordination platforms and systems to track progress, engage experts or manage resources across departments are absent $[84,85]$. Competing priorities and a lack of incentives to coordinate may also prevent collaboration [86]. In order for intersectoral collaboration to occur, departments must set up regular communication systems, clarify incentives, targets and performance indicators, and empower strong leadership [85-88]. Bureaucratic resource systems also need to support collaboration, which requires buy-in from people within a range of departmental bureaucracies [89].

In addition to top-down changes, bottom up action is required to promote government accountability for implementation. Community awareness and education campaigns about drowning risks and responses should be integrated with intervention delivery, helping to raise public interest and accountability. Garnering community support may stimulate more pressure on local governments to meet implementation targets [90-92].

Development of new programs based on policy principles In addition to using existing government programs for the implementation of drowning reduction interventions, the development of new interventions that align with policy goals and principles may also be feasible. New programs that align with existing policy are more likely to be accepted by government and implemented once their efficacy has been established [23].

These results show that the provision of first responder training is highly supported in disaster risk reduction and climate change policy. The establishment of safe spaces for children is also acknowledged in children's and education policy, supporting the implementation of barrier-based interventions. Hence, working with government stakeholders to develop new programs that cater to policy goals is an additional strategy for developing drowning reduction interventions.

\section{Limitations of the study}

Firstly, not all state-level policy documents may have been available online to the public. While we made contact with state government offices for access to any other policy documents that may exist, they were nonresponsive. To ensure we were basing analysis on all publicly-available data, we re-checked all websites after the analysis to ensure no policy documents were missed. Secondly, there were limited primary studies of government program implementation from the Sundarbans region, so the search was extended to all West Bengal. Some of the findings of implementation reach and success of government programs may not be applicable to implementation in the Sundarbans region. Further research is needed that conducts primary qualitative work with program implementers in this region to identify specific enablers and barriers for the region.

\section{Implications for future study}

This study provides guidance on how the implementation of drowning programs in the Sundarbans region may leverage on government programs. However, implementation will involve the expertise and buy-in of both government and Sundarbans communities. To understand both policy and community-level perceptions and considerations of drowning program design and implementation, qualitative work with relevant stakeholders is required. Community participatory approaches will enable development of an acceptable and pragmatic model for the region, given its unique geography and lowresource setting [93, 94].

\section{Conclusions}

Drowning is a major cause of child death by injury in India, particularly in the rural, coastal Sundarbans region in the state of West Bengal. However, no interventions are currently implemented in this region to address this issue, such as supervised childcare, home-based barriers, swim and rescue training or first responder training as recommended by World Health Organization. This paper identified government policy and programs that mapped against the recommended interventions and 
could be leveraged for the implementation of a sustainable drowning program. The analysis enabled the identification of 'win-win' solutions that not only addressed the drowning problem, but also enabled the government to meet its short and long term goals, including across different sectors, to enhance program sustainability and feasibility [95]. Drowning interventions that leverage and improve existing structures such as the ICDS program, ASHA program and SHG programs can be both beneficial in reducing drowning and improving the implementation of these schemes for government. New drowning interventions that cater to policy targets, such as those around upskilling communities in first response and providing safe spaces for children at home, also warrant consideration. As drowning disproportionately impacts children and marginalised, rural communities, addressing drowning will also play a key role in supporting West Bengal to meet its SDG targets, particularly those relating to under-5 mortality and reducing inequities [96].

\section{Supplementary information}

Supplementary information accompanies this paper at https://doi.org/10 1186/s12889-020-08868-2.

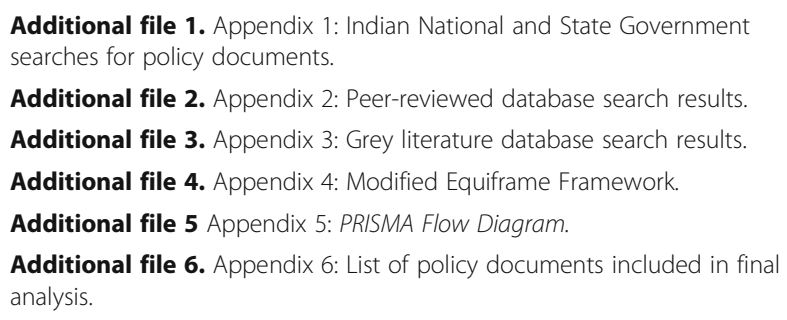

\section{Abbreviations}

ASHA: Accredited Social Health Activist; ECCE: Early Childhood Care and Education; ECE: Early Childhood Education; ICDS: Integrated Child Development Scheme; LMICs: Low-and middle-income countries; MNREGA: Mahatma Gandhi National Rural Employment Guarantee Act 2005; NABARD: National Bank for Agriculture and Rural Development; NCW: National Commission for Women; NHRC: National Human Rights Commission; SHG: Self-Help Group; 6SQulD: Steps for Quality Intervention Development; SDGs: Sustainable Development Goals; WHO: World Health Organization; VHSNCs: Village Health, Sanitation and Nutrition Committees

\section{Acknowledgements}

Not applicable

\section{Consent for publications}

Not applicable.

\section{Authors' contributions}

MG and JJ formulated the research questions and AZ provided guidance on use of frameworks and policy analysis methodology. MG designed the search strategy, conducted searches, conducted analysis and drafted the manuscript with inputs from $A Z$ and JJ. All authors have read and approved the manuscript.

\section{Funding}

Not applicable.
Availability of data and materials

Data sharing is not applicable to this article as no datasets were generated or analysed during the current study.

Ethics approval and consent to participate

Not applicable.

\section{Competing interests}

The authors declare that they have no competing interests.

\section{Author details}

${ }^{1}$ The George Institute for Global Health, University of New South Wales, Level 5/1 King St, Newtown, NSW 2042, Australia. ${ }^{2}$ Health, Rights and Development (HEARD@UNSW), School of Social Sciences, Faculty of Arts and Social Sciences, UNSW Australia, Morven Brown Building, Kensington 2052, Australia. ${ }^{3}$ Injury Division, The George Institute for Global Health, New Delhi 110025, India.

Received: 18 February 2020 Accepted: 7 May 2020

Published online: 15 May 2020

\section{References}

1. World Health Organization. Drowning Fact Sheet Geneva: World Health Organization; 2018 [Available from: https://www.who.int/news-room/factsheets/detail/drowning.

2. van Beeck EF, Branche CM, Szpilman D, Modell JH, Bierens JJLM. A new definition of drowning: towards documentation and prevention of a global public health problem. Bull World Health Organ. 2005;83(11):853-856. doi: S0042-96862005001100015.

3. Meddings D, Hyder AA, Ozanne-Smith J, Rahman A. Global report on drowning: preventing a leading killer. Geneva, Switzerland: World Health Organization; 2014.

4. Alonge O, Hyder AA. Reducing the global burden of childhood unintentional injuries. Arch Dis Child 2014;99(1):62-69. doi: 10.1136/ archdischild-2013-304177.

5. Tyler MD, Richards DB, Reske-Nielsen C, Saghafi O, Morse EA, Carey R, et al. The epidemiology of drowning in low-and middle-income countries: a systematic review. BMC Public Health 2017;17(1):413. doi: 10.1186/s12889017-4239-2.

6. Menon GR, Singh L, Sharma P, Yadav P, Sharma S, Kalaskar S, et al. National burden estimates of healthy life lost in India, 2017: an analysis using direct mortality data and indirect disability data. Lancet Glob Health 2019;7(12): e1675-e1e84. doi: 10.1016/S2214-109X(19)30451-6.

7. O'Donnell A, Wodon Q. Climate change adaptation and social resilience in the Sundarbans. New York: Routledge; 2015

8. Kanjilal B, Mazumdar PG, Mukherjee M, Mondal S, Barman D, Singh S, et al. Health care in the Sundarbans (India): Challenges and plan for a better future.: Institute of Health Management Research 2010.

9. The World Bank. Building Resilience for Sustainable Development of the Sundarbans: Strategy Report. The World Bank:; 2014. Report No.: 88061-IN.

10. Jagnoor J, Bassani DG, Keay L, Ivers RQ, Thakur JS, Gururaj G, et al. Unintentional injury deaths among children younger than 5 years of age in India: a nationally representative study. Inj Prev 2011;17(3):151-155. doi: 10. 1136/ip.2010.029934

11. Lukaszyk C, Ivers RQ, Jagnoor J. Systematic review of drowning in India: assessment of burden and risk. Inj Prev 2018. doi: 10.1136/injuryprev-2017042622

12. Mahadevia Ghimire K, Vikas M. Climate Change - Impact on the Sundarbans: A case study. Int Sci J Environ Sci. 2012:2:7-15.

13. DasGupta R, Shaw R. An indicator based approach to assess coastal communities' resilience against climate related disasters in Indian Sundarbans. Plan Manag 2015;19(1):85-101. doi: 10.1007/s11852-014-0369-1.

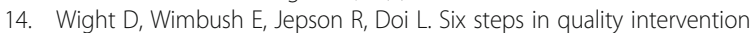
development (6SQuID). J Epidemiol Community Health 2016;70(5):520. doi: 10.1136/jech-2015-205952

15. Pawson R, Tilley N, Tilley N. Realistic evaluation. London: Sage; 1997.

16. Moore GF, Audrey S, Barker M, Bond L, Bonell C, Hardeman W, et al. Process evaluation of complex interventions: Medical Research Council guidance. BMJ 2015;350. doi: 10.1136/bmj.h1258.

17. O'Neill J, Tabish H, Welch V, Petticrew M, Pottie K, Clarke M, et al.. Applying an equity lens to interventions: using PROGRESS ensures consideration of 
socially stratifying factors to illuminate inequities in health. J Clin Epidemiol. 2014;67(1):56-64. doi: doi.org/10.1016/j.jclinepi.2013.08.005.

18. Baru R, Acharya A, Acharya S, Kumar AKS, Nagaraj K. Inequities in Access to Health Services in India: Caste, Class and Region. Econ Pol Wkly. 2010;45(38): 49-58.

19. Mukherjee AK. Empowerment through government subsidized microfinance program: do caste and religion matter? Int J Soc Econ. 2015;42(1):2-18.

20. Sengupta P, Jaba G. Enrolment, Dropout and Grade Completion of Girl Children in West Bengal. Econ Pol Wkly. 2002;37(17):1621-37.

21. Jagnoor J, Gupta M, UI Baset K, Ryan D, Ivers R, Rahman A. The association between water, sanitation and hygiene (WASH) conditions and drowning in Bangladesh. J Water Health 2019;17(1):172-178. doi: 10.2166/wh.2018.243.

22. de Zoysa I, Habicht JP, Pelto G, Martines J. Research steps in the development and evaluation of public health interventions. Bull World Health Organ. 1998;76(2):127-33.

23. Shiffman J, Smith S. Generation of political priority for global health initiatives: a framework and case study of maternal mortality. Lancet. 2007; 370:9. doi: 10.1016/S0140-6736(07)61579-7.

24. Uzochukwu B, Onwujekwe O, Mbachu C, Okwuosa C, Etiaba E, Nyström ME, et al. The challenge of bridging the gap between researchers and policy makers: experiences of a health policy research group in engaging policy makers to support evidence informed policy making in Nigeria. Glob Health 2016;12(1):67. doi: 10.1186/s12992-016-0209-1.

25. Schünemann H. The GRADE Working Group. GRADE Handbook for Grading Quality of Evidence and Strength of Recommendations. Schünemann $\mathrm{H}$, Brożek J, Guyatt G, Oxman A, editors: Cochrane; 2013.

26. Oliver S, Kavanagh J, Caird J, Lorenc T, Oliver K, Harden A, et al. Health promotion, inequalities and young people's health: a systematic review of research. London: EPPI-Centre, Social Science Research Unit, Institute of Education, University of London; 2008.

27. Amin M, MacLachlan M, Mannan H, Tayeb SE, Khatim AE, Swartz L, et al. EquiFrame: A framework for analysis of the inclusion of human rights and vulnerable groups in health policies. Health Hum Rights. 2011;13(2):82-101

28. Snilstveit B, Oliver S, Vojtkova M. Narrative approaches to systematic review and synthesis of evidence for international development policy and practice. J Dev Effect. 2013;4(3):409-29.

29. Gupta A. Governing population: the integrated child development services program in India. Hansen, Thomas Blom; Stepputat, Finn, eds States of imagination: ethnographic explorations of the postcolonial state Durham, NC; London: Duke University Press, 2001 viii, 423p (Politics, history, and culture) 2001. p. 65-96.

30. Rao N. Children's rights to survival, development, and early education India: The critical role of the Integrated Child Development Services program. Int J Early Child. 2005;37(3):15-31,126.

31. The World Bank. West Bengal: institutional strengthening of gram Panchayats program II (ISGPP-II). Delhi, India: The World Bank; 2017.

32. Palriwala R, Neetha N. Care arrangements and bargains: Anganwadi and paid domestic workers in India. Int Labour Rev. 2010;149(4):511-27.

33. Jain M. India's struggle against Malnutrition - is the ICDS program the answer? World Dev. 2015;67:72-89.

34. Biswas AB, Das DK, Roy RN, Saha I, Shrivastava P, Mitra K. Awareness and perception of mothers about functioning and different services of ICDS in two districts of West Bengal. Ind J Public Health. 2010;54(1):33-5.

35. Sharma A, Sen RS, Gulati R. Early childhood development policy and programming in India: Critical issues and directions for paradigm change. Int J Early Child. 2008:40(2):65-83.

36. Rao N, Kaul V. India's integrated child development services scheme: challenges for scaling up. Child Care Health Dev 2018;44(1):31-40. doi: 10. 1111/cch.12531.

37. Dutta A, Ghosh S. Impact of integrated child development scheme on child malnutrition in West Bengal, India. Matern Child Nutr. 2017;13(4):(e12385). doi: $10.1111 /$ mcn.12385.

38. Samanta S, Basu SS, Haldar D, Sarkar AP, Saren AB, Sarkar GN. Status of early childhood education under integrated child development services scheme in Bankura municipality, West Bengal. Indian J Public Health 2017;61(4):261266. doi: 10.4103/ijph.IJPH_369_16.

39. Maity B. Interstate differences in the performance of Anganwadi centres under ICDS scheme. Econ Pol Wkly. 2016;51 (51):59-66. doi::

40. Pada G. Putting the smallest first: child malnutrition in India. Economist. 2010;396(8701):34
41. Paul VK, Sachdev HS, Mavalankar D, Ramachandran P, Sankar MJ, Bhandari $\mathrm{N}$, et al. Reproductive health, and child health and nutrition in India: Meeting the challenge. Lancet. 2011;377(9762):332-49.

42. Mula G, Sarker SC. Performance of Different Financial Institutions in the Perspective of Microfinance in Sitai Block of West Bengal. Econ Affairs. 2013; 58(3):229-37.

43. Das S, Patnaik BCM. Microfinance in Eastern India: The Role Played by Regional Rural Banks. Ind J Finance. 2015;9(11):45-59.

44. Sankaran M. Micro Credit in India: An Overview. World Rev Entrepreneurship, Manag Sustainable Dev. 2005;1 (1):91-100. doi:.

45. Singh N. A critical review of self-help group - Bank linkage Programme of micro-finance in India. Paradigm. 2008;12(1):50-56. doi: 10.1177/ 0971890720080107.

46. Somasekhar K. Financial Inclusion Through Self Help Groups for Rural Livelihoods - An Analysis. Int J Soc Sci. 2015:4(4):289-296. doi: 10.5958/23215771.2016.00006.5

47. Saha S, Annear PL, Pathak S. The effect of self-help groups on access to maternal health services: evidence from rural India. Int J Equity Health 2013; 12:36. doi: 10.1186/1475-9276-12-36.

48. Singh JB, Gupta MS. Micro-finance Sector in India--How Has Its Outreach Been So Far? Int J Appl Bus Econ Res. 2013;11(1):47-72.

49. Das SK. Expansion of Micro-financing through Swarnajayanti Gram Swarojgar Yojana: Experience in West Bengal. Econ Affairs. 2010;55(2):180-6.

50. Naganahalli VS. Progress of women Self-Help Groups in India: a statistical analysis. Golden Res Thoughts. 2013;2(12).

51. Datta SK, Singh K. Determinants of income generation and financial performance through self-help groups. J Soc Serv Res 2014;40(1):97-110. doi: 10.1080/01488376.2013.845129.

52. Srinivasan N. Sustainability of SHGs. Karmakar, KG, ed Microfinance in India New Delhi: Sage Publications, 2008 489p2008. p. 176-87.

53. Ghosh S. Democracy and human development: recent legislation in India. Dev Pol Rev 2016:34(4):539-561. doi: 10.1111/dpr.12162.

54. Maity B. Microfinance: Women from the margin to the mainstream. J Rural Dev. 2016:35(1):17-38.

55. Bera SK. A Study of SHG-Microfinance Initiative in Purbo Midnapore District of West Bengal. Econ Affairs. 2011;56(2):107-16.

56. Das A, Datta TK. The Economic Impact of Microcredit Disbursed Through SHGs: A Study in Purulia District, West Bengal. IUP J Entrepreneurship Dev. 2014;11(4):7-23.

57. Paul PK, Kuri PK. Micro-credit in Combating Rural Poverty: A Micro Study in West Bengal. Finance Ind. 2014;28(1):103-18.

58. Chatterjee S, Apartment M. Self-help groups and economic empowerment of rural women: A case study. Int J Educ Manag Stud. 2014;4(2):103-7.

59. Banerjee S, Mukherjee V, Haldar SK. Understanding Development: An Indian Perspective on Legal and Economic Policy Springer; 2016.

60. Shylendra HS, Bhirdikar K. 'Good governance' and poverty alleviation Programmes: a critical analysis of the Swarnjayanti gram Swarozgar Yojana. Int J Rural Manag 2005;1 (2):203-221. doi: 10.1177/097306800500100204.

61. Tripathi AK. Spread of the self-help group-Bank linkage Programme in India: potential Vis-à-Vis achievements. J Asian Afr Stud 2014;49(2):215-233. doi: 10.1177/0021909613485698.

62. Thekkekara TF. Impact of SGSY on SHG: bank linkges. Karmakar, KG, ed Microfinance in India New Delhi: Sage Publications, 2008 489p2008. p. $188-218$.

63. Chatterjee S, DuttaGupta S, Upadhyay P. Sustainability of microenterprises: an empirical analysis. Benchmarking. 2018;25(3):919-931. doi: 10.1108/BIJ-072017-0185.

64. Mukherjee AK, Kundu A. SGSY: How much beneficial across socio-religious communities? J Rural Dev. 2013;32(2):213-35.

65. Government of India. Village Health Sanitation \& Nutrition Committee 2013 [Available from: http://nhm.gov.in/communitisation/village-health-sanitationnutrition-committee.html.

66. International Institute for Population Sciences. District level household and facility survey (DLHS-4), 2012-13: India, West Bengal. Mumbai: IIPS; 2014.

67. Kumar S, Prakash N. Impact of the Village Health and Sanitation Committee on health-care utilisation: findings from propensity score matching in India. The Lancet. 2013;381(S2). doi: 10.1016/S0140-6736(13)61331-8.

68. Supath Gramyodyog Sansthan. Performance of Rajiv Gandhi National Crèche Scheme for Children of Working Mothers. In: Planning Commission Gol, editor. Gujarat: Supath Gramyodyog Sansthan 2013. 
69. Kundu A, Talukdar S. Employment generation among women in NREGS: a synthesis on the basis of micro level field investigation. J Econ Pol Econ 2017:4(1):107-120. doi: 10.1453/jepe.v4i1.1182.

70. Dheeraja C, Madhuri NV, Daimari A. Research study on factors facilitating participation of women in mahatma Gandhi NREGS. In: Ministry of Rural Development, government of India, editors. Rajendranagar, Hyderabad: National Institute of Rural Development; 2013.

71. National Health Mission. Update on ASHA program: January 2016. New Delhi: National Health Mission,; 2016.

72. Bomble $P$, Jungari S. Role and importance of accredited social and health activists (ASHA) in accomplishing goals and successes of National Rural Health Mission. Sharma S, editor. Bookwell: Delhi; 2015.

73. Mondal N, Murhekar MV. Factors associated with low performance of accredited social health activist (ASHA) regarding maternal care in Howrah district, West Bengal, 2015-'16: an unmatched case control study. Clin Epidemiol Glob Health 2018;6(1):21-28. doi: 10.1016/j.cegh.2017.05.003.

74. Biswas R, Chattapadhyay D. Monitoring and continuing education system of ICDS Programme in Hooghly District, West Bengal. Ind J Public Health. 2001; 45(3):99-103.

75. Mamgain RP, Diwakar GD. Elimination of identity-based discrimination in food and nutrition Programmes in India. IDS Bull 2012;43(SUPPL. 1):25-31. doi: 10.1111/j.1759-5436.2012.00343.x.

76. Ghosh S, Das BK. Exploring demographic and socio-economic factors influencing utilization of integrated child development services. Asia-Pac Popul J. 2011:26(1):11-38.

77. Qadiri F, Manhas S. Parental perception towards preschool education imparted at early childhood education centers. Stud Home Commun Sci 2009:3(1):19-24. doi: 10.1080/09737189.2009.11885271.

78. Ved R, Scott K, Gupta G, Ummer O, Singh S, Srivastava A, et al. How are gender inequalities facing India's one million ASHAs being addressed? Policy origins and adaptations for the world's largest all-female community health worker programme. J Hum Resourc Health 2019;17(1):3. doi: 10.1186/ s12960-018-0338-0.

79. Verick S. Female labor force participation and development. IZA World of Labor. 2018. doi: 10.15185/izawol.87.v2.

80. Knoepfel P, Larrue C, Varone F, Hill M. Public policy analysis. Bristol, UK: Policy Press; 2011.

81. Sabatier $\mathrm{P}$, Mazmanian D. The implementation of public policy: A framework of analysis. Policy Stud J. 1980;8(4):538-60.

82. Brinkerhoff DW, Bossert TJ. Health governance: principal-agent linkages and health system strengthening. Health Policy Plan. 2013;29(6):685-693. doi: 10. 1093/heapol/czs132\%J Health Policy and Planning.

83. Kahn LH. Integrating a one health approach into epidemiology to improve public policy. Int J Epidemiol 2019;48(6):1737-1739. doi: 10.1093/ije/dyz178.

84. Zaidi S, Bhutta Z, Hussain SS, Rasanathan K. Multisector governance for nutrition and early childhood development: overlapping agendas and differing progress in Pakistan. BMJ Glob Health. 2018;3(Suppl 4).

85. Glandon D, Meghani A, Jessani N, Qiu M, Bennett S. Identifying health policy and systems research priorities on multisectoral collaboration for health in low-income and middle-income countries. BMJ Glob Health. 2018; 3(Suppl 4).

86. Emerson K. Collaborative governance of public health in low- and middleincome countries: lessons from research in public administration. BMJ Global Health. 2018;3(Suppl 4). doi:.

87. Bennett S, Glandon D, Rasanathan K. Governing multisectoral action for health in low-income and middle-income countries: unpacking the problem and rising to the challenge. BMJ Global Health. 2018;3(Suppl 4). doi:.

88. Rasanathan K, Atkins V, Mwansambo C, Soucat A, Bennett S. Governing multisectoral action for health in low-income and middle-income countries: an agenda for the way forward. BMJ Global Health. 2018;3(Suppl 4). doi:.

89. Thomas JW, Grindle MS. After the decision: implementing policy reforms in developing countries. World Dev 1990;18(8):1163-1181. doi: 10.1016/0305750X(90)90096-G.

90. Korten DC. Community organization and rural development: a learning process approach. Public Adm Rev 1980;40(5):480-511. doi: 10.2307/ 3110204.

91. Bullard RD, Johnson GS. Environmentalism and public policy: environmental justice: grassroots activism and its impact on public policy decision making. J Soc Issues 2000;56(3):555-578. doi: 10.1111/0022-4537.00184.

92. Burstein $P$. The impact of public opinion on public policy: a review and an agenda. Polit Res Q 2003;56(1):29-40. doi: 10.1177/106591290305600103.
93. Thomas-Slayter B. Participatory approaches to community change: building cooperation through dialogue and negotiation using participatory rural appraisal. In: de Rivera J, editor. Handbook on building cultures of peace. New York, NY: Springer New York; 2009. p. 333-348.

94. Bogart LM, Uyeda K. Community-based participatory research: partnering with communities for effective and sustainable behavioral health interventions. Health Psychol 2009;28(4):391-393. doi: 10.1037/a0016387.

95. Commission on Social Determinants of Health. Closing the gap in a generation: health equity through action on the social determinants of health: Final Report of the Commission on Social Determinants of Health. Geneva: World Health Organization; 2008.

96. United Nations Economic and Social Council. Progress towards the Sustainable Development Goals: Report of the Secretary-General. United Nations, Economic and Social Council; 2017.

\section{Publisher's Note}

Springer Nature remains neutral with regard to jurisdictional claims in published maps and institutional affiliations.

\section{Ready to submit your research? Choose BMC and benefit from:}

- fast, convenient online submission

- thorough peer review by experienced researchers in your field

- rapid publication on acceptance

- support for research data, including large and complex data types

- gold Open Access which fosters wider collaboration and increased citations

- maximum visibility for your research: over $100 \mathrm{M}$ website views per year

At BMC, research is always in progress.

Learn more biomedcentral.com/submissions 